\title{
Predicting lifetimes of components in power station engineering plant
}

\author{
Andrew Morris ${ }^{1}$, Amit Puri ${ }^{2}$, Chris Maharaj ${ }^{2}$, Miltiadis Kourmpetis ${ }^{2}$, \\ Mikael Sjödahl ${ }^{3}$ and John P. Dear ${ }^{2}$ \\ ${ }^{1}$ E.ON UK, Nottingham, UK \\ ${ }^{2}$ Imperial College London, London, UK \\ ${ }^{3}$ Luleå University of Technology, Luleå, Sweden
}

\begin{abstract}
Today, there is increasing demand for power station plant to be operated cost effectively and to reliably maintain required electrical supply. This requires minimising the risk of having to shut-down the plant for emergency repairs. Of paramount importance, is plant operating integrity and well prepared and executed maintenance programmes. This paper reports on the recent developments to the Auto-Reference Creep Management \& Control (ARCMAC) system used by E.ON UK. This includes achieving biaxial strain measurement with increased resolution and the employment of Digital Image Correlation (DIC).
\end{abstract}

\section{Nomenclature}

ARCMAC - Auto-Reference Creep Management \& Control

DIC - Digital Image Correlation

ARAMIS - DIC software

GOM - Optical Measurement Company

$\varepsilon_{y} \quad-$ strain in the y-direction (vertical)

$\varepsilon_{x} \quad-$ strain in the x-direction (horizontal)

$G_{L} \quad-$ installed gauge length ( $\mathrm{mm}$ ) between the weld pins

$A \quad-$ manufactured reference distance $(3 \mathrm{~mm})$

$B(t) \quad-$ distance between two outer targets on the gauges.

\section{Introduction}

The life of steam pipes in power stations very much depends upon the material's steady state creep rate. Essential is that monitoring sensors are of a very rugged design well able to endure the demanding conditions related to environment of high-pressure steam pipes. This is to provide creep data for remnant life assessment of pipes when a power generating plant is closed down for periodic 
maintenance. A combined approach using the ARCMAC gauge system developed by E.ON UK and Digital Image Correlation (DIC) to study the variations in creep strain on steam pipe networks will be presented. This is particularly useful, for example, when monitoring parent pipe material, welds and other localised features on the pipe network. Both circumferential and axial strain rates are monitored to provide for analysis to identify when pipes are approaching their reliable end-of-life point. This provides for planned replacement of pipes as part of cost effective management of power stations. The E.ON UK ARCMAC gauge system for measuring strain has been developed in the light of experience of its use to achieve high confidence ratings in the data obtained. This creep strain monitoring system provides data that can be used to underwrite life extension of power stations, many of which are now in operation in the UK beyond 225000 hours.

\section{ARCMAC System}

This is a creep management system developed by E.ON UK Power Technology. The creep strain rate is calculated by comparing two captured images of a pair of gauges, the first of which is captured after installation and the subsequent one after two year's operation. Typically a secondary creep strain rate on main steam CMV pipes is ca. $2 \times 10^{-8}$ hour $^{-1}$ and the unit might operate for 12000 hours over a 2 year period, for which there is an expected creep strain accumulation of 240 microstrain.

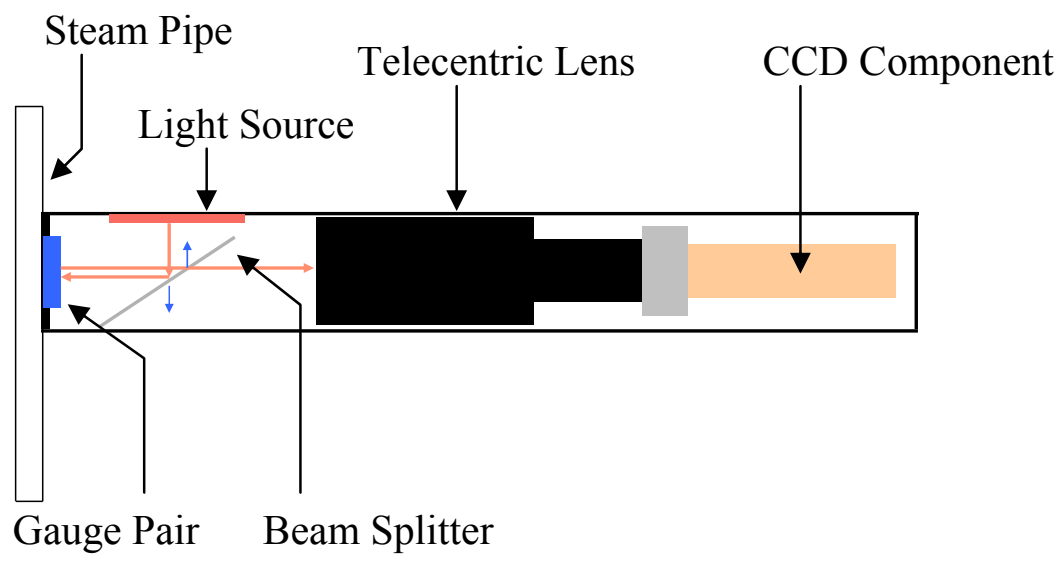

Figure 1. Schematic of ARCMAC camera unit.

The ARCMAC system has been designed to work with readily available equipment. For on-site measurement it requires a portable hand-held camera unit with image capture logger. This has been designed with a telecentric lens, beam splitter and diffuse light source. These are arranged so as to provide illumination along the axis of the camera, as shown in Fig. 1. 


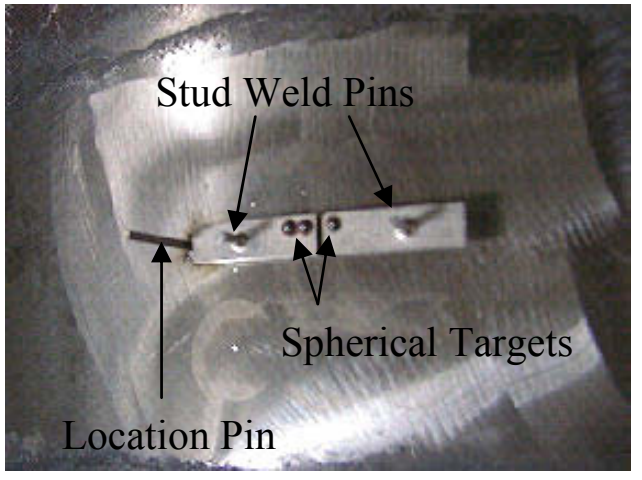

a

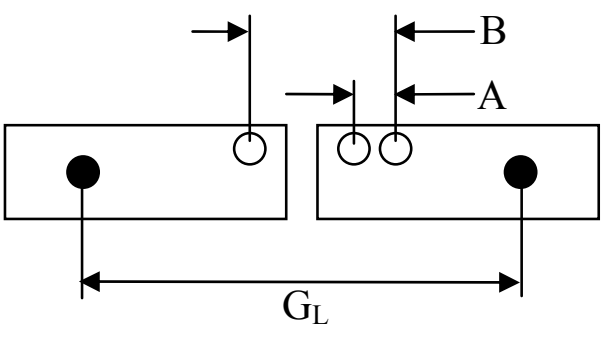

Ratio $=\mathrm{B} / \mathrm{A}$

$\mathrm{b}$

Figure 2. ARCMAC gauges: a) Located on stream pipe; b) Ratio calculation.

The gauges themselves are constructed from Inconel which allows welding onto the pipe surface. Mounted upon the gauges are SiNi target spheres, as shown in Fig. 2a above. It is important is that the SiNi target spheres are appropriately illuminated so as to provide for the needed measurement. The three target spheres provide images in the form of three circular points of light. Two of these points of light come from the two spheres on one Inconel gauge and these provide a reference dimension. Image analysis software calculates the distance between the centers of each light spot. This information is used then to calculate the ratio between the light spots, as shown in Fig. 2b, which is subsequently used to evaluate strain via Equation (1), where Ratio $_{0}$ is from the initial image, and Ratio $_{t}$ is from the subsequent one. Used in conjunction with the MPC project OMEGA methodology, [2], this will allow estimation of component remnant life.

$$
e=\frac{\text { Ratio }_{t}-\text { Ratio }_{0}}{G_{L} / A}
$$

\subsection{Improved Resolution of ARCMAC System}

Recently, the light source for the ARCMAC system has been upgraded from an electroluminescent strip to a high intensity Light Emitting Diode (LED) array. The increased illumination has produced an improvement in resolution and this is assessed using an Extensometer Calibration Rig (ECR) supplied by the National Physical Laboratory (NPL). The ECR has been calibrated in compliance with the BS EN 10002-4:1995 and ASTM E83-96 standards. The maximum error over a nominal extension of the ECR of $0-2.5 \mathrm{~mm}$ was $0.1 \mu \mathrm{m}$. Such a precise rig allowed the resolution of the ARCMAC camera to be obtained.

The ECR consists of a moving and fixed bar, upon which the two gauges were attached with a nominal gauge length of $31 \mathrm{~mm}$, and the displacement between the two can thus be accurately altered. Three datum images are captured and then the gap between the two parts of the gauge is increased in steps of 1 or $5 \mu \mathrm{m}$. At the 
end of each step, three images are captured. Once the maximum calibration extension has been reached the same process is repeated, this time decreasing the gap until the datum position is reached.

Site installation experience has shown that the camera unit will not always be positioned precisely normal to the target gauge. This is one of the reasons for the choice of a telecentric lens in the camera unit; it is tolerant of angular misalignments to a reasonable degree. However the downside is that the optimum distance between the lens and the target is at around $92 \mathrm{~mm}+/-3 \mathrm{~mm}$, so that the lens must be located inside the camera unit with reasonable precision. In addition, the working distance of the lens coupled with its physical length means that the camera unit is approximately $450 \mathrm{~mm}$ long. This means that some plant locations are inaccessible with this arrangement. Hence several calibration runs have been undertaken with the camera re-positioned to represent conditions on site.

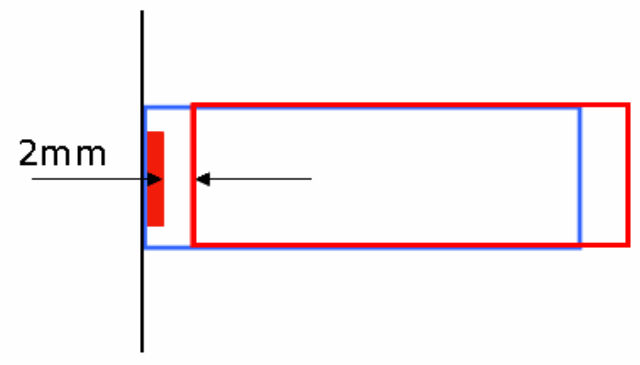

a)

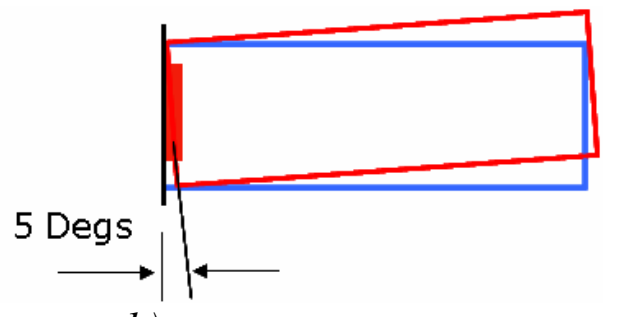

b)

Figure 3. Example of types of camera offset: a) Axial; b) Angular.

To assess the accuracy of the system with the new light source, a comparison of percentage error obtained for the two different light sources for optimum working conditions and for situations when the camera is displaced from its optimum position is used. The purpose of these experiments was to demonstrate the tolerance of the strain measurement system. The two divisions of displacement considered are axial offset and angular offset, as highlighted in Fig. 3. For this image the blue box represents the camera at optimal position, and the red box represents the camera at the offset position. The details of the comparison are:

- Axial positioning: Camera unit normal to the gauge, with the axial position varied from nominal position to $+4 \mathrm{~mm}$, in steps of $1 \mathrm{~mm}$ ( 5 stages in total).

- Angular misalignment: Camera unit positioned at the nominal position, with angular misalignments up to $\pm 10^{\circ}$, in steps of $5^{\circ}$ (5 stages in total).

Fig. 4 shows the comparison of the two light sources for the nominal operating position. The improvement at low values of strain and higher values is significant. A vertical red line is drawn at the 161 micro-strain limit (160 micro-strain corresponds to a displacement of $5 \mu \mathrm{m}$ ). The error of the LED system is less than 
$10 \%$ for strain values as low as 64 micro-strain. The comparisons at the offset stages are shown for axial and angular offsets in Tables 1 and 2 respectively. These values were extracted at the 160 micro-strain point, and it can be seen that there is definite advantage gained by using the high intensity LED at the lower strains.

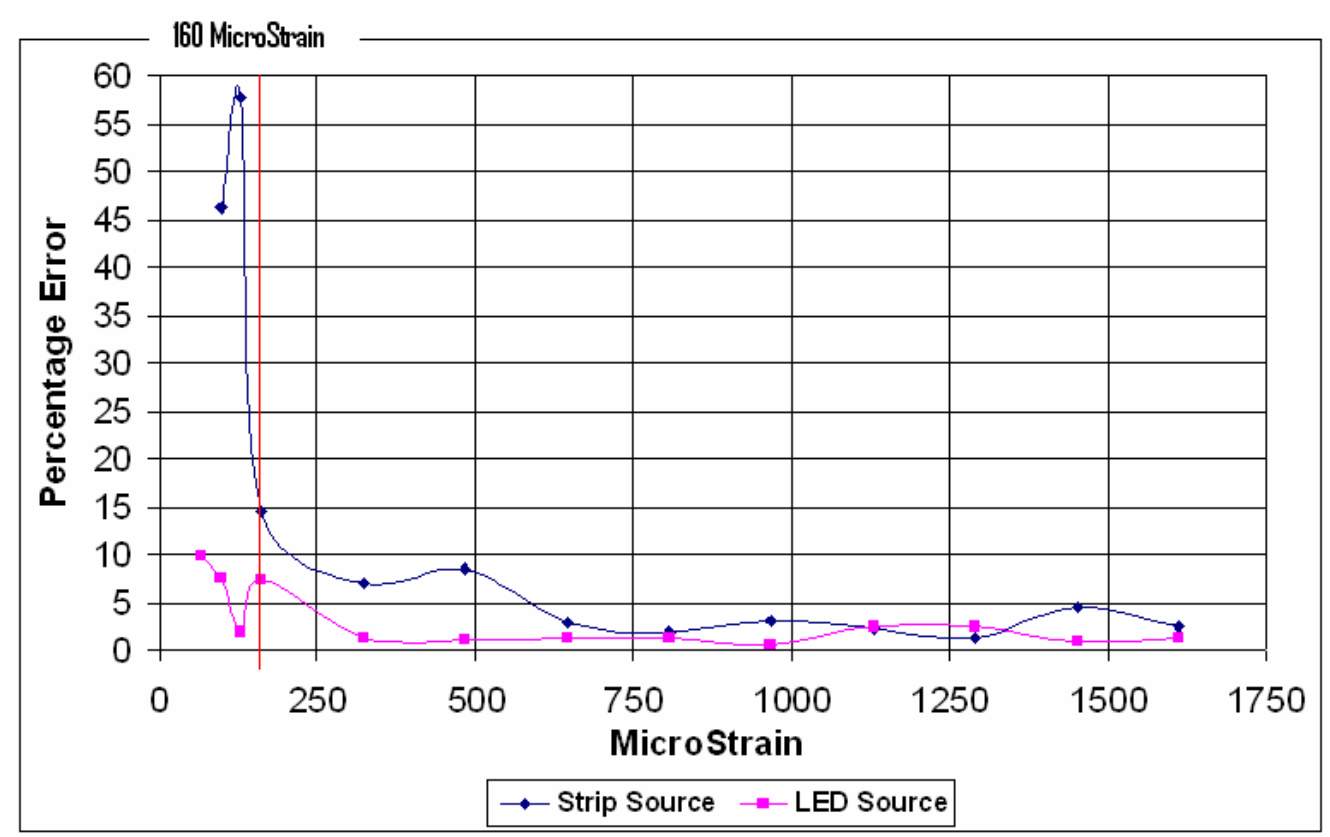

Figure 4. Comparison of LED source and Strip Light Source for nominal operating conditions.

Table 1. Percentage error for axial offset.

\begin{tabular}{|l|c|c|}
\hline & \multicolumn{2}{|c|}{ Percentage error obtained } \\
\hline Offset & Strip Source & LED source \\
\hline Nominal $(0 \mathrm{~mm})$ & 15 & 7 \\
\hline $1 \mathrm{~mm}$ & 12 & 2 \\
\hline $2 \mathrm{~mm}$ & 11 & 12 \\
\hline $3 \mathrm{~mm}$ & 37 & 2 \\
\hline $4 \mathrm{~mm}$ & 6 & 3 \\
\hline
\end{tabular}

Table 2. Percentage error for angular offset.

\begin{tabular}{|l|c|c|}
\hline & \multicolumn{2}{|c|}{ Percentage error obtained } \\
\hline Offset & Strip Source & LED source \\
\hline Nominal $\left(0^{\circ}\right)$ & 15 & 7 \\
\hline $5^{\circ}$ left & 21 & 4 \\
\hline $10^{\circ}$ left & 39 & 6 \\
\hline $5^{\circ}$ right & 22 & 3 \\
\hline $10^{\circ}$ right & 8 & 2 \\
\hline
\end{tabular}


In conclusion, angular misalignment, as well as axial displacement, has very little effect in reducing the accuracy of the ARCMAC camera when using the new LED source. In addition, the confidence strain value has been improved from 160 to 64 micro-strain. Fig. 5 shows three different creep rates with the resolution limits for the LED and strip sources as horizontal dotted lines. It is apparent with the new LED source, it is possible to measure with confidence the lowest creep rate of ca. $1 \times 10^{-8}$ hour $^{-1}$ after 2 years (12000 hours of operation). It is to be noted that typical secondary creep strain rate on main steam CMV pipes are ca. $2 \times 10^{-8}$ hour $^{-1}$.

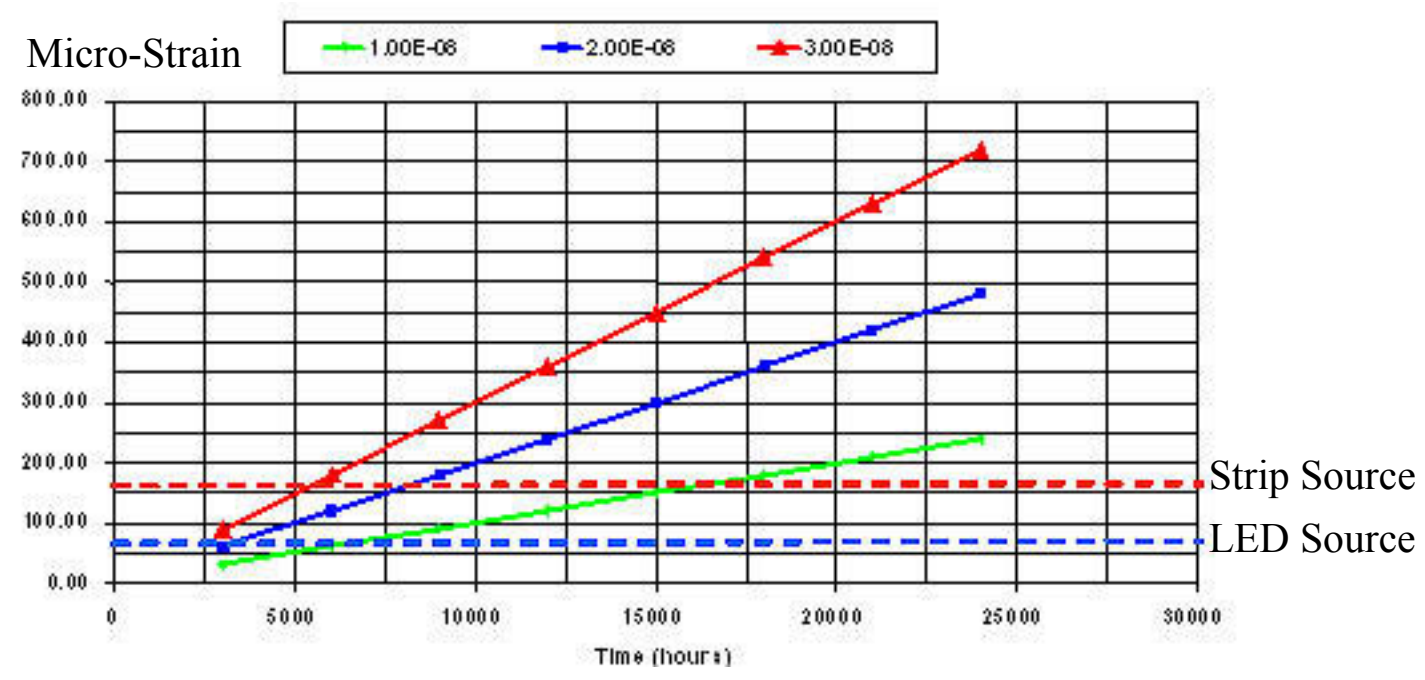

Figure 5. Improvement in creep measurement for LED source versus Strip light source.

\section{Digital Image Correlation}

DIC uses a series of digital images of a surface under various levels of load, upon which a high density random paint pattern has been applied [3]. The software divides the image into squares of pixels known as facets, from which the interfacet displacements can be calculated between load levels, as shown in Fig. 6. For greater accuracy, the GOM ARAMIS software [4], uses an averaging method based on a group of facets. The evaluated displacement matrix can be differentiated to produce a full-field strain map of the surface. This allows for easy visualisation of the strain experienced by the component. In addition to this, the strain variation along a drawn line can be obtained, which allows precise numerical analysis of the observed strain. 


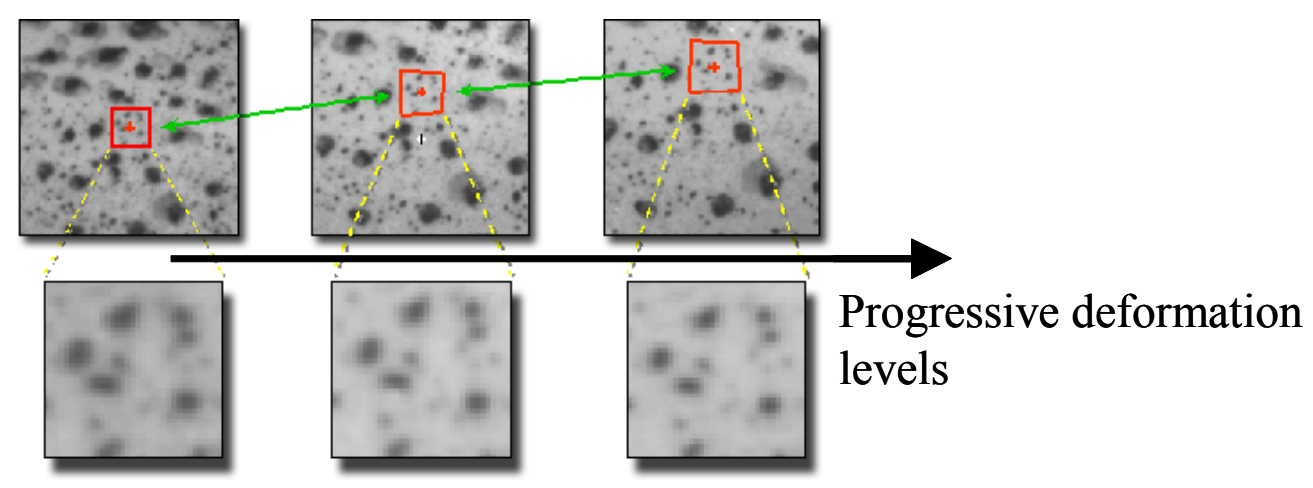

Figure 6. Example of DIC solution method [5].

The system requires the use of digital cameras. The ARAMIS system is able to capture strains as low as 500 micro-strain [6], which is more than twice the expected strain on a steam pipe after two years in service. Therefore, DIC will be used in conjunction with the ARCMAC gauges to evaluate any unusual strain distribution surrounding the gauge area, such as occurs with internal weld defects. The presence of such a defect is likely to cause higher strain levels in the pipe, and it is important to estimate the contribution of this towards the creep rate estimation.

\subsection{Tensile Testing on Pipe Material}

The typical pipe material used is CMV steel, whose major alloying elements consist of Chromium (0.5\%), Molybdenum (0.5\%) and Vanadium (0.25\%). Upon hardening the material achieves a maximum tensile strength of $610 \mathrm{MPa}$ [7]. The alloying elements serve to increase synergistically the high temperature creep rupture strength by reducing the coarsening mechanism of spheroidisation, which would occur in plain carbon steel at elevated temperatures [8]. Tests were conducted on $250 \mathrm{~mm}$ long tensile dog-bone specimens with a gauge length of $150 \mathrm{~mm}$ and thickness $6 \mathrm{~mm}$. The width of the specimen was $37.5 \mathrm{~mm}$ along the gauge length. To simulate a weld imperfection, a small defect $3 \mathrm{~mm}$ deep, $15 \mathrm{~mm}$ long and $3.5 \mathrm{~mm}$ wide, was machined onto the back surface of the specimen, with the aim of performing DIC on the front side. This would allow simulation of non-destructive testing of an internal defect within a welded section of pipe, as might be encountered on-site.

The experiments were compared to a Finite Element (FE) model (ABAQUS version 6.6-1) using modulus of elasticity, yield strength, and Poisson's ratio values obtained from [7] and [9]. Work hardening values for the plastic range of the material were obtained by conducting a tensile test on a similar CMV sample without a defect. Elements used were of the second order, reduced integrated, 3D 20-node brick type. These elements were chosen as they were suitable for plastic deformation modelling and did not suffer from volumetric shear locking. Through end friction gripping, the specimen was constrained to move except in 
the Y-direction. A surface traction load was applied up to the maximum test load of $60 \mathrm{kN}$ at both gripping ends.

Fig. 7 shows a comparison of observed $\varepsilon_{x}$ and $\varepsilon_{y}$ obtained from both ABAQUS and ARAMIS at two different load levels. At both load levels the effects of the defect are clearly visible as a non-uniform strain pattern. The shape of the defect causes shear failure, which results in elevated strain levels at $45^{\circ}$. In addition, there is a region of high compressive strain in the region of reduced material cross-section for the $\varepsilon_{x}$ plot, as would be expected.
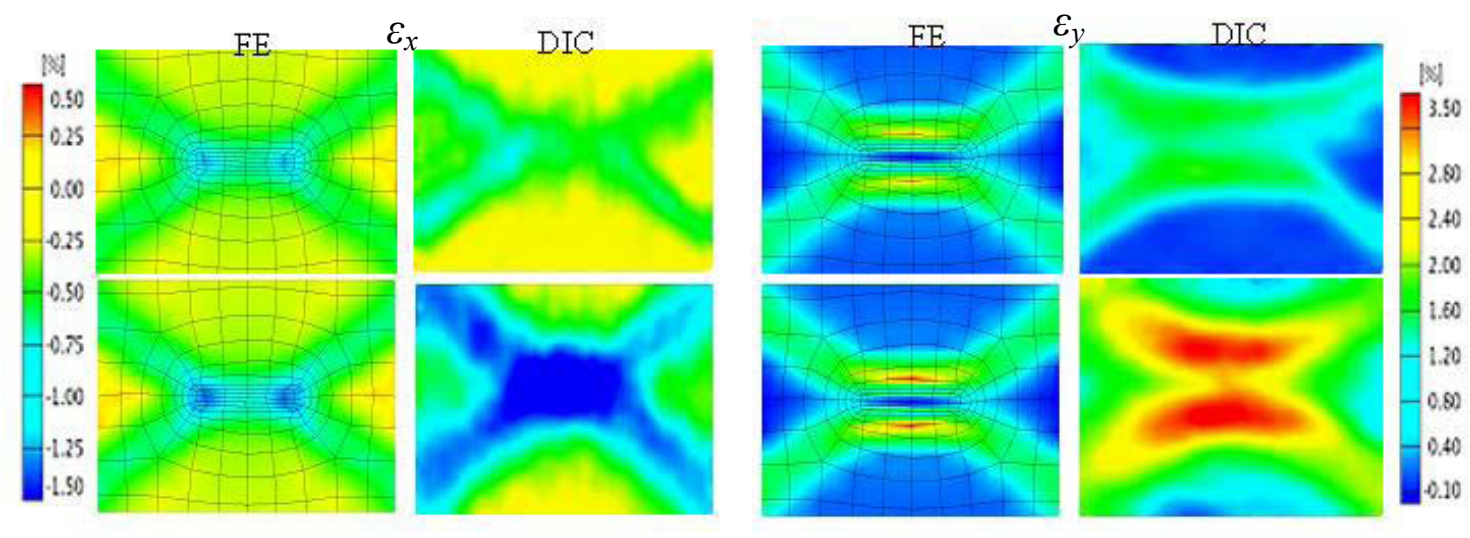

Figure 7. FE and DIC comparison: $\varepsilon_{x}$ and $\varepsilon_{y}$ plots for $88 \%$ (top row) and $100 \%$ (bottom row) of maximum load.

Table 3. Comparison of FE and DIC strain values for $100 \%$ load.

\begin{tabular}{|l|c|c|c|c|}
\hline \multirow{2}{*}{} & \multicolumn{2}{|c|}{$\boldsymbol{\varepsilon}_{\boldsymbol{y}}$} & \multicolumn{2}{c|}{$\boldsymbol{\varepsilon}_{\boldsymbol{x}}$} \\
\cline { 2 - 5 } & FE & DIC & FE & DIC \\
\hline Centre of defect & $\sim 0 \%$ & $\sim 2.8 \%$ & $\sim-1.0 \%$ & $<-1.5 \%$ \\
\hline Close to defect & $>3.5 \%$ & $>3.5 \%$ & $\sim 1.0 \%$ & $\sim 1.0 \%$ \\
\hline Remote from defect & $<0.1 \%$ & $<0.1 \%$ & $0 \%$ & $0 \%$ \\
\hline
\end{tabular}

Table 3 summarises the correlation between FE and DIC. As can be seen there is good agreement between the two methods at points near and remote from the defect, substantiating the DIC method. There is a clear difference between the two methods, however, at the centre of the defect. To be noted is that, the DIC could be overestimating the absolute strain in both $\mathrm{X}$ and $\mathrm{Y}$ directions at this point.

There are three potential reasons for this, the first being that the DIC is more roughly averaging the image when formulating the displacement matrix. In other words, the DIC is unable to detect the step change in the observed strain over this small distance. The second possible explanation is that the FE mesh is modelled in such a way to promote this particular anomaly, and further refinements may result in closer agreement. The third possible explanation is that the thickness reduction in the centre is causing out-of-plane strain, a feature which would be 
picked up by DIC as inaccurate in-plane strain, when using only one camera, but can be modelled exactly by FE. However, the use of a telecentric lens would minimise this effect. It is probable that the combined effects of these three processes will result in the differences shown in Table 3 and the fact that the majority of values do agree well can be considered as a positive result.

Another difference between the two sets of results is that the FE produces clearly defined crossed shaped regions of high strain, whereas the DIC is more diffuse. The principle reason for this is that the FE model does not incorporate inhomogeneities in the material. A further interesting difference between the two is that the formation of this distinctive pattern was observed at earlier strains in the FE model, specifically $36 \%$ and $54 \%$ for $\varepsilon_{y}$ and $\varepsilon_{x}$ respectively, as shown in Fig. 8. The most likely reason is that the resolution of the applied DIC pattern may be insufficient to pick up the slight difference in observed strain at the lower load levels.
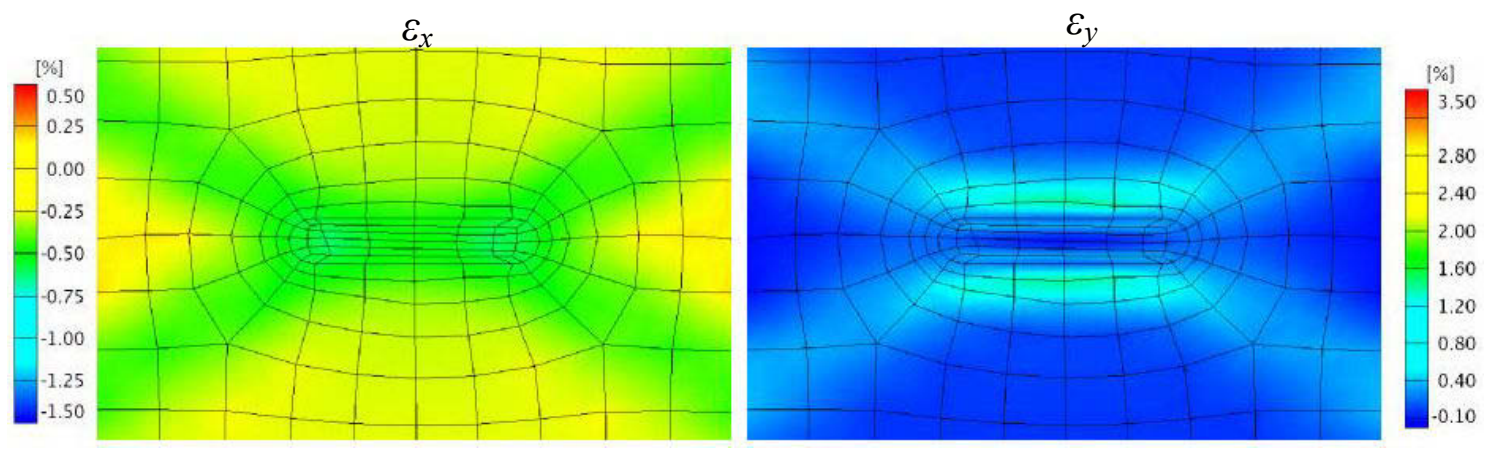

Figure 8. $\varepsilon_{x}$ (left) and $\varepsilon_{y}$ (right) strain maps for FE model at $36 \%$ and $54 \%$ respectively.

Further tests will incorporate using more refined FE models, in addition to comparison work with electronic strain gauges and ARCMAC gauges. However, the initial results show that the DIC system is able to detect effectively subsurface defects within steam pipe material.

\section{Combined ARCMAC and DIC}

Following the calibration of the system using the LED light source, it was decided that specimens with ARCMAC gauges and DIC speckle coatings should be exposed to harsh real-life loading conditions, e.g. $568^{\circ} \mathrm{C}$ temperature and strain measurements should be provided by the ARCMAC camera. Hence, tensile dog-bone specimens were prepared from high pressure CMV steel pipe material. The specimens were designed with biaxial ARCMAC gauges on one side and a speckle pattern on the other side. This way the ARCMAC camera will produce strain measurements from both the ARCMAC gauges and the speckle pattern. High temperature paint was used as above to form a speckle pattern on 
the surface of the CMV tensile specimens. The ARCMAC camera recorded a reference picture of the speckle pattern. The tensile specimens were then placed in an oven at $600^{\circ} \mathrm{C}$ for 1000 hours, which modestly exceeds typical operational temperatures of a high-pressure steam pipe. After exposure, the ARCMAC camera was used to record further images of biaxial ARCMAC gauges and high temperature paint speckle patterns.

The purpose of these experiments was to see if it was possible to obtain DIC strain data from a speckle patch that had been subjected to high temperature ageing conditions. Different finishes and coatings were applied on the specimens in order to investigate the environmental effect on the speckle pattern. Figs. 9a and $9 \mathrm{~b}$ show images obtained with the ARCMAC camera of the speckle paint applied on a specimen with airbrush and aerosol respectively. The paint used here was FIRWOOD 75 [10], which has been rated as being able to withstand temperatures as high as $600^{\circ} \mathrm{C}$. Fig. 9c shows an image of the ARCMAC gauges taken with the ARCMAC camera before the specimen was placed in the oven.

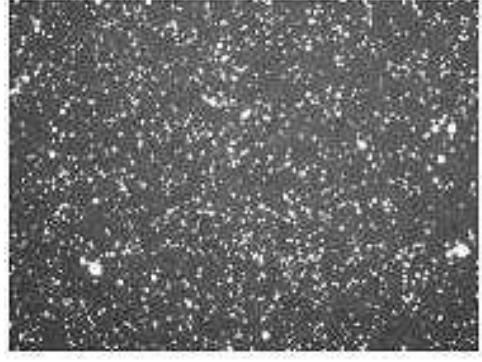

a)

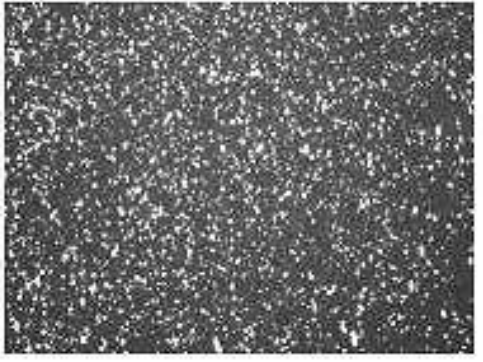

b)

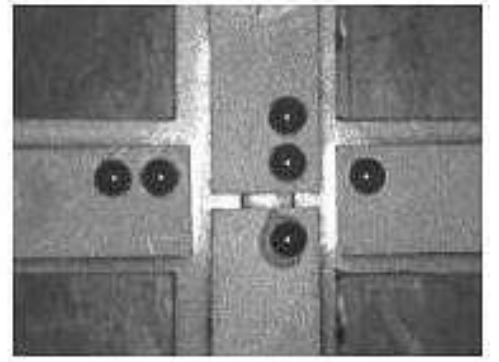

c)

Figure 9. ARCMAC images: a) FIRWOOD 75 high temperature airbrushed paint, b) FIRWOOD 75 high temperature aerosol paint; c) Biaxial ARCMAC gauge.

a) Airbrush

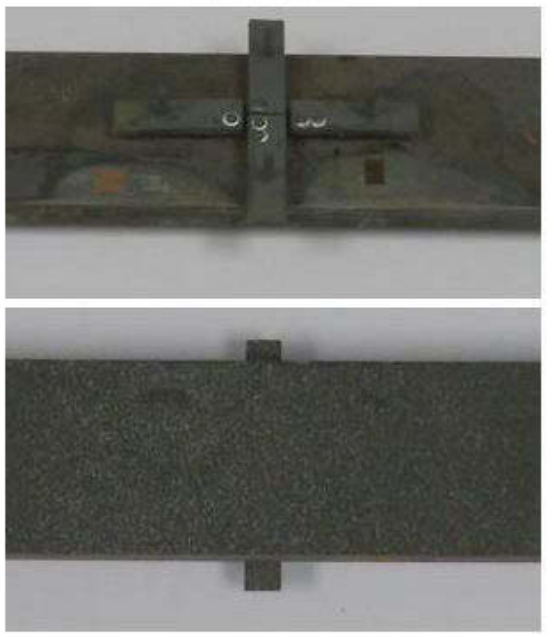

b) Aerosol

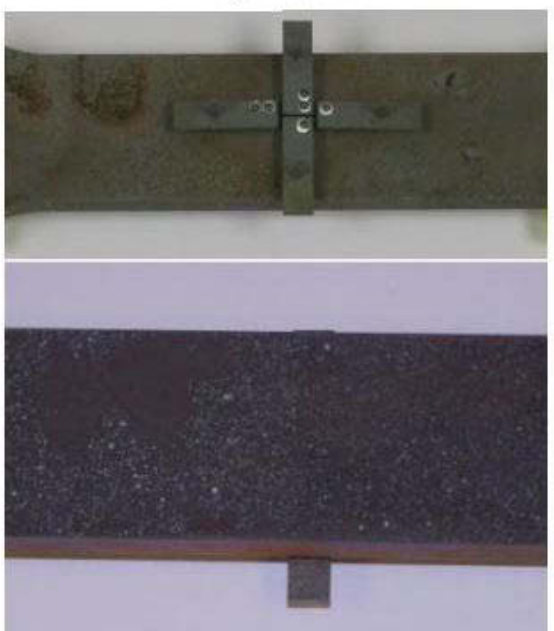

Figure 10. Biaxial ARCMAC gauges with speckle paint pattern after exposure in an oven at $600^{\circ} \mathrm{C}$ for 1000 hours: a) airbrush paint finish and b) aerosol paint finish. 
Of the two speckle patterns, the airbrush applied speckle pattern survived better than the aerosol applied speckle paint finish. However, good DIC data was obtained from both finishes. Other paints and finishes are being investigated for DIC measurement studies.

The ARCMAC camera combined with DIC is being used to study specimens with different defects and other features. One example is a specimen with a central circular hole of $3 \mathrm{~mm}$ diameter. Images from the ARCMAC camera were imported into DIC software for strain analysis, in this case ARAMIS. The results are shown in Fig. 11 for two different load levels, and good DIC strain fields have been obtained using the ARCMAC camera.

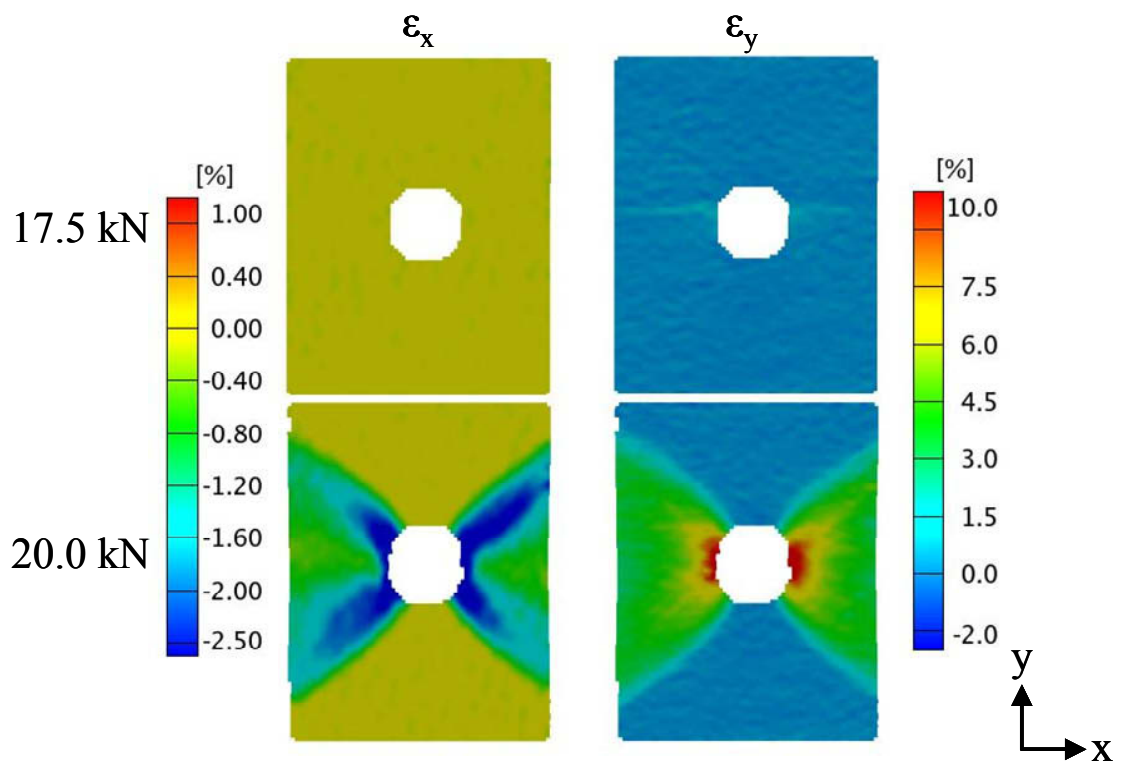

Figure 11. Comparison of $\varepsilon_{x}$ and $\varepsilon_{y}$ maps obtained with the ARCMAC camera for specimen loaded in tension (in the y direction) with a central circular hole.

\section{Conclusion}

The new LED source for the ARCMAC system has improved strain resolution limits. This has allowed low creep rates of ca. $1 \times 10^{-8}$ hour $^{-1}$ to be measured with confidence over 2 years (12000 hours of operation). In addition, the DIC strain maps obtained from tensile dog-bone specimens with rear surface defects have been substantiated with FE analysis. Furthermore, speckle coatings using high temperature paints have been applied to CMV steel material and subjected to high temperature conditions. It has been found that the integrity of these speckle patches is maintained and speckle coating images recorded by the ARCMAC camera system can be analysed using DIC software to produce strain field maps. The ARCMAC camera is capable of capturing ARCMAC gauges and at the same time DIC strain patterns. 


\section{Acknowledgments}

The authors acknowledge the support of E.ON UK and James Mithen [11] for his helpful contribution.

\section{References}

[1] Morris, A. Dear, J. and Kourmpetis, M. "Life Assessment by Monitoring Biaxial Strain-Rates in High Temperature Steam Pipelines", Proc. of ASME PVP 2006/ICPVT-11 Pressure Vessels and Piping Division Conference, July 23-27, 2006, Hyatt Regency Vancouver, BC, Canada, Paper Number: 93065.

[2] Prager, M. Journal of Pressure Vessel technology, 1995, Vol. 117, (1995), p. 95.

[3] Sjodahl, M. "Accuracy in Electronic Speckle Photography", Applied Optics, Vol. 36, No. 13, pp. 2875-2885, 1997.

[4] http://www.gom.com - Deformation measurement system developed by GOM mbH, Germany.

[5] http://www.correlatedsolutions.com/index.php?option=com_content\&task=v iew\&id=23\&Itemid=36 - Principle of Digital Image Correlation, Correlated Solution, West Columbia, USA.

[6] GOM mbH, "ARAMIS User Manual: ARAMIS v5.4.1", GOM mbH Germany, 2005.

[7] BS3604-1:1990, Steel pipes and tubes for pressure purposes: ferritic alloy steel with specified elevated temperature properties. Specification for seamless and electric resistance welded tubes, British Standards Publishing Limited, London, 1990.

[8] API RP 571, Damage Mechanisms Affecting Fixed Equipment in the Refining Industry, American Petroleum Institute, 2003.

[9] BS806, Specification for the design and construction of ferrous piping installations for and in connection with land boilers. British Standards Publishing Limited, London, 1993. 
[10] http://www.firwood.co.uk/webapp/wcs/stores/servlet/ProductDisplay?langId=$1 \&$ storeId=10001\&catalogId=10001\&productId=26255 - Firwood 75 High Temperature Resisting Paint information sheet, Firwood Paints LTD, UK.

[11] Mithen, J. ARCMAC and DIC Applied to Power Station Engineering, Final Year MEng Project, Imperial College London, 2007. 